\title{
Changes in the offing
}

It comprises 411 pages, has a Ministerial Forward, a Chairperson's Introduction and an Executive Summary of well over 14000 words. Add in some nifty formulae and graphs and you have the Report of the Ministerial Committee for the Review of the Funding of Universities. To capture and summarise the detailed content of so substantial a report in a thousand words or so would be an impossible task. But there are four aspects of the Report that might be of interest to readers of this Journal: the review team's recommendations will be modelled to determine their effects on South African universities, emphasis is placed on steering the higher education system towards differentiation, there are proposed changes to the rewards for publication and a proposed shift in focus in the allocation of Research Development Grants.

In order to test the recommendations made in the Report, a technical team and parallel reference group have been established to determine what those recommendations will mean for each of the 25 universities in the system. Due to be completed by the end of 2014 , the outcome will form the basis for a draft funding policy and framework which, after consultation with the sector, will become the basis for future funding. It is intended that the new policy and framework will then be phased in over a number of years - although a so-called 'disadvantage factor' will be introduced to the existing funding framework and implemented immediately, using new funds, to address the weak financial circumstances of some historically (and currently) disadvantaged institutions.

The emphasis on creating and maintaining a differentiated higher education system develops the idea set out in the White Paper on Post School Education and Training released in January this year. In the White Paper's section on universities, the point is made that

[t]here is broad agreement that South Africa needs a diverse university sector which is purposefully differentiated in order to meet a range of social, economic and educational requirements.... Since the establishment of the [Department of Higher Education and Training], it has been recognised that the principle of differentiation must apply beyond the universities to the entire postschool system.

In his Foreword to the Report, Minister Blade Nzimande takes the point further:

\footnotetext{
A number of our universities are world-class academic institutions at the cutting edge of research in various spheres, while others may be better situated to make teaching their primary purpose. This brings the need for a differentiated university sector to the fore. Both teaching and research are critical for the development of highly skilled academics, workers and researchers, and it is important that both these activities are adequately funded. It is government's vision that all universities should at least develop research niche areas and that all universities will participate in research and innovation, albeit to various extents.
}

The recommendations set out in the Report are quite specific:

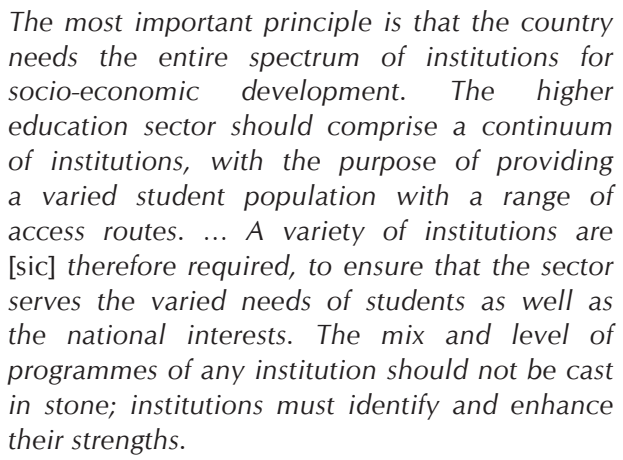

It is unclear as to how well this will be received by some vice-chancellors.

The position taken by the Review Committee on financial rewards for publications starts on a positive note, pointing out that the funds available for research productivity are limited and that '[i]t is therefore essential that more funding be allocated by Treasury to ensure that the success in increasing research outputs of universities be sustained and further incentivised'. There are, however, recommended changes regarding how research publications should be assessed, with an emphasis on rewarding excellence and quality rather than quantity. To achieve this aim, accredited journals would be ranked and assigned to three categories based on their impact factors published by, for example, the Web of Science. Publication rewards would then be based on the category of journal in which research is published. The proposal does, however, pose some problems: no account is taken of the fact that 'high' impact factors vary widely among disciplines, nor that many South African based journals do not appear amongst the published citation indexes. It is also recommended that papers which are the products of collaborative research, whether nationally or regionally, should receive higher rewards than papers that do not involve collaboration.

In order to support emerging scholars, it is suggested that two new journals might be established (one in the humanities and social sciences and a second in the natural sciences) with the specific aim of carrying first-time papers published by postgraduate students - and it is recommended that these journals would best be administered by the Academy of Science of South Africa. Although it is unclear what is meant by 'research outputs from the performing, creative and visual arts,' the Report recommends that these should also be assessed and, where appropriate, suitably funded.

Finally (for this Leader), there is the matter of Research Development Grants. The Report indicates that 'there is evidence' to suggest that the current, ring-fenced Research Development Grants are not being used effectively and that the focus should shift to universities and universities of technology that have limited research capacities, with funding aimed at developing a critical number of research niche areas around centres of excellence. Such a shift would, the Report argues, require a careful analysis of the research strengths of targeted institutions with an emphasis on the status of research development strategies and plans. In general, however, the view is expressed that the goal of building research capacity for the entire system should be re-affirmed and that special attention should be given to support for emerging scholars - with the implication that such support should be a factor included in general funding as it will be defined in the new policy and framework.

HOW TO CITE: Butler-Adam J. Changes in the offing. S Afr J Sci. 2014;110(3/4), Art. \#a0061, 2 pages. http://dx.doi.org/10.1590/sajs.2014/a0061 
Towards the end of his Introduction to the Report, the Chairperson of the Ministerial Committee, Mr Cyril Ramaphosa, observes that

South Africa's funding of higher education, even though significant, does not compare favourably to other countries. In 2011, the state budget for universities as a percentage of gross domestic product (GDP) was $0.75 \%$ compared to $0.78 \%$ for Africa as a whole, and $1.21 \%$ for the Organisation for Economic Co-operation and Development (OECD) countries. Given the important role of higher education in the production of skills, research and innovation, in the mitigation of socio-economic inequalities, and in the realisation of the state's development agenda, the level of funding needs to improve. However, for additional funding to have any meaningful impact, it is necessary to address the inefficiencies in the system.

Let us hope that the final version of the funding policy and framework will help to address the inefficiencies and allow for that much needed additional injection of financial support. 